Revista Iberoamericana. Vol. LXVI, Núm. 190, Enero-Marzo 2000, 147-161

\title{
LAS RESONANCIAS DE UN NOMBRE: GABRIELA MISTRAL
}

\author{
POR \\ LiLA Zemborain \\ Baruch College / CUNY
}

El hecho de que Gabriela Mistral se refiera a su propio nombre y a su seudónimo en algunos poemas me lleva a reflexionar sobre la propiedad humana de nombrar. A nivel de texto literario, la cuestión del nombre puede enfocarse, según Leroy Breunig, desde dos puntos de vista complementarios: por un lado, como nombre de autor que firma un texto, o sea como "firma de autor"; y por el otro, como elemento del texto.

An author's use of a false name, a nom de plume, whether limited to the title page or scattered as an actual element in a literary work, can set up a relationship between author and text and establish connections that would not exist were the author content to sign the work with his or her real name (256).

Las conexiones que pueden establecerse entre texto y nombre conforman lo que Breunig llama una poética del seudónimo, puesto que lo que se logra es una poetización del nombre. La poetización del nombre implica una forma de autofiguración, dada la identidad entre autor, sujeto del enunciado y sujeto de la enunciación. En este trabajo me voy a referir en primer lugar a las figuraciones que Gabriela Mistral elabora en torno a su nombre y a su seudónimo como "firma de autor". Y luego, voy a explorar las resonancias que el seudónimo tiene en las distintas formas de representación que desarrolla en su poesía. El seudónimo mistraliano prefigura la representación de un sujeto femenino que expande, entre otros, los conceptos de intelectualidad, sexualidad y nacionalidad.

LA POETIZACIÓN DEL NOMBRE

El nombre propio, mal llamado propio para las mujeres, puesto que es un nombre que se hereda o se adquiere por vía masculina, es una imposición que condiciona las formas en que el sujeto femenino se autofigura. El nombre de pila de Gabriela Mistral, Lucila de María del Perpetuo Socorro Godoy Alcayaga, revela una serie de subordinaciones que la "dueña" del nombre soporta y que la inscriben dentro de un orden social. Lucila pertenece a María del Perpetuo Socorro, hay una subordinación religiosa a una figura que da perpetuo socorro a quienes lo necesiten. A su vez, en el apellido, Godoy, está implícita la idea de ser hija de Jerónimo Godoy, un padre de ascendencia española, que ha abandonado a su familia cuando Lucila tenía tres años. El apellido subordina a Lucila a una autoridad masculina representada 
por un padre ausente. El apellido es la evidencia de esa ausencia. Alcayaga: el apellido vasco de Petronila, la madre, que implica la subordinación femenina a la genealogía masculina.

Lucila tiene conciencia de la esclavitud que implica su nombre y comienza su carrera poética escondiéndolo. Según palabras de Mistral:

Cuando recién comenzaba a escribir unas prosas muy malas en el periódico de mi pueblo, firmaba simplemente con una "Y" (citado en Giménez 37).

La "Y” podría considerarse como el primer seudónimo que usa Mistral. Es extraña esta elección de la penúltima letra del abecedario. En primera instancia se puede interpretar que Lucila anula su identidad al reducirla simplemente a una letra que no alcanza para expresar el "YO”. Pero no elige "X" que es la letra del anonimato sino la conjunción coordinante copulativa "Y", cuya función es unir, repetir y diferenciar. Al estar ausentes los términos enlazados la "Y" se transforma por un lado en un interrogante que señala una incógnita: “¿Y?”, y por el otro en la posibilidad de ser algo más, un plus, algo que se agrega a una serie: “esto, esto y esto". En el contexto del seudónimo la "Y” figura entonces un sujeto que no llega a ser un yo autoral, que no sabe aún qué destino le espera, pero que apunta hacia la adición de algo que se enlazará a lo existente.

Posteriormente Lucila encuentra otras formas para representar su yo autoral. Entre 1904 y 1908, cuando tiene entre quince y dieciocho años, colabora con el periódico Coquimbo de La Serena firmando con varios seudónimos que según Jaime Concha, se inscriben en un "susurrante intimismo de la época, una de las modalidales que tomó el posmodernismo en Hispanoamérica”(56). Los seudónimos “Alguien”, “Soledad” y “Alma”, figuran un "alguien” que está solo pero en profunda comunicación con su alma. Concha lee acertadamente ese "Alguien” como un ser que ha dejado de ser nadie, pero que aún no es un ser determinado. Yo agregaría que el neutro “alguien”, al contener potencialmente ambos sexos, es a-genérico, y que por un lado, Lucila lo usa como pantalla para esconder su sexo, pero por el otro, parece indicar que el derecho a la escritura, o el derecho a nombrar, es común a ambos sexos.

Es interesante la comparación de estos seudónimos mistralianos con los seudónimos que eligieron otras mujeres escritoras contemporáneas a Mistral para firmar sus primeros escritos puesto que revelan una postura bien diferente por parte de Mistral. Delmira Agustini, según Sylvia Molloy, comienza a publicar poesía en 1902 a los dieciseis años “bajo el seudónimo espléndidamente cursi de Joujou” (“Dos lecturas” 57). Y Teresa de la Parra publica sus primeros cuentos en 1915 bajo el seudónimo de Fru-Frú (Bosch 46). Ambas escritoras inscriben sus seudónimos en un discurso esperable para las mujeres: Agustini se figura como el engarce de una niña que juega, con una joya: jouet-bijou, y de la Parra no encuentra mejor cosa para figurarse que la onomatopeya del ruido que produce la seda al rozarse: fru-frú. El estereotipo por excelencia del mundo femenino: inmadurez, domesticidad, accesorios, vestimentas. Estos seudónimos que pueden leerse como otra de las "tretas del débil" (Ludmer 53) de la mujer escritora para insertarse en el mundo intelectual, se oponen al seudónimo elegido por Lucila, quien se ubica por medio del seudónimo neutro en un nivel de igualdad con sus colegas masculinos. 
El uso de un seudónimo neutro en Mistral revela que el patronímico femenino es inapropiado para las intenciones literarias de la joven poeta. No sólo muestran Gilbert y Gubar que el nombre femenino es impropio porque se inscribe en un discurso patriarcal, sino que también es “impropio” porque no es “propio”, no es de su propiedad. Las mujeres no poseen el nombre ni para nombrarse a sí mismas ni tampoco para nombrar a los otros, para dar nombres.

For women in our culture, however, a proper name is at best problematic, even as it "inscribes" her into the discourse of society by designating her role as her father's daughter, her patronymic effaces her matrilineage and thus erases her own position in the discourse of the future. Her "proper" name, therefore, is always improper because it is not, in the French sense, propre, her own, either to have or to give ("Ceremonies" 24).

A partir de 1905, el patronímico de Mistral (alternado con sus primeros seudónimos) sufre una serie de "desfiguraciones” y "cortes” hasta que procede a su total desaparición. Según Marcelo Bahamonde, en este año Lucila publica algunos poemas en "La Voz de Elqui” de Vicuña y firma como Lucila Godoi Alcayaga. La “y” griega cae y se la reemplaza por la “i” latina instituída por la ortografía de Andrés Bello (Bahamonde 102). Por un lado, entonces, se altera el nombre español del padre, chilenizándolo. Por el otro, se elimina de plano el nombre religioso, que probablemente no usaría. En los años sucesivos continúa publicando con este nombre en La voz de Elqui y en La Reforma. Posteriormente, alterna este nombre con el de Lucila Godoy, con lo cual elimina el nombre materno.

En 1911 Lucila tiene 21 años y reside en Antofagasta donde se desempeña como Inspectora General del Liceo de Niñas y Profesora de Castellano. En el mes de enero presenta su primer texto, una prosa poética titulada “Navegando”, para que se la publiquen en el diario El Mercurio de Antofagasta. Su nombre sufre un significativo error de imprenta: aparece como Anibal Godoy Alcayaga. Las disculpas del diario se hacen ver al número siguiente:

Ayer publicamos un artículo literario Navegando con quien quiso favorecernos la distinguida escritora señorita Lucila Godoy Alcayaga, profesora de castellano [...], pero una lamentable equivocación hizo aparecer cambiado el nombre de la autora (citado en Bahamonde 116).

Como puede observarse en la figura de Lucila ya está presente la futura representación mistraliana de la "maestra escritora”, que no sólo surge de la poesía de Mistral sino también de la forma en que se la presentaba en los círculos literarios. Evidentemente a la "distinguida escritora señorita [...] maestra de castellano” no le debe haber hecho mucha gracia la "lamentable equivocación”. Pero se debe tener en cuenta que en aquellos tiempos no era muy corriente que una mujer publicara sus escritos en los diarios. Baste a modo de ejemplo ver la nota editorial que publica este mismo diario al celebrar su quinto año de labor en diciembre de 1911, casi un año después del error tipográfico:

Para el desarrollo de nuestra labor, de la cual nos sentimos orgullosos, hemos contado con el concurso entusiasta de dignísimos caballeros que han colaborado en este diario con 
artículos e informaciones. De entre ellas, nos es grato mencionar con intenso agradecimiento los nombres de la señorita Lucila Godoy Alcayaga y de los señores Pedro León Parodi, Galvarino Ponce, Gregorio Mella, Luis Salinas Vega, Ismael Larraín Maqueño [...] (citado en Bahamonde 53).

Y sigue una lista innumerable de nombres masculinos que el diario termina con un “etc., etc.” Hay que notar aquí el embrollo retórico que produjo la inclusión de un nombre femenino en esta lista. Por empezar, los colaboradores son “dignísimos caballeros”, o sea que Lucila vuelve a ser Anibal. Luego se buscó que las colaboraciones incluyeran un femenino, “artículos e informaciones”, "las informaciones”, para que el enlace con la frase siguiente, tuviera al menos alguna concordancia con la persona que encabeza la lista: "De entre ellas", ¿a quién se refiere, a "las" informaciones o a "las" dignísimos caballeros? Obviamente, el nombre de la distinguida señorita resultaba una incomodidad que explica en cierta medida los errores tipográficos.

No sólo hay una incomodidad por parte del entorno masculino, ante la joven escritora. Marcelo Bahamonde cita otro texto significativo de esta época de Lucila en Antofagasta, sin dar sus fuentes, donde Lucila revela sus difíciles relaciones con la gente que la rodea, a causa de su carácter diferente.

Noto que no tengo condiciones para ganarme la cordialidad fácil de la gente que me rodea. O me profesan una veneración que no me agrada o me demuestran desconfianza o una cierta dolorosa frialdad con agria descortesía. Me resulta extraño pensar que no consigo esa relación humana espontánea y natural. Capaz que esto se deba a que todo en mi vida tiene un fondo intelectual. Primero soy eso: una intelectual. Y después, pero muy después, recién soy mujer, sin mucha gracia humana, y sin mucha comunicación. ¿Y cómo, entonces, hierve en mí esa fuerza pasional por estrujar mis dolores? Ah. Romelio Ureta, ingrato y traicionero, que te desengañaste sin contármelo. No puedo decir que te odio porque no hay odio en mis caudales interiores. Nunca he sentido odio, en cambio, me confieso pasional. Vivo ciega de pasión y poesía, tratando de convertir los dos torrentes en los impulsos profundos de mi vida. Me confieso pasional y por ello no le pido perdón a nadie. Quien se acerque a mí deberá soportarme como soy. De lo contrario, es preferible que frunza el ceño, como lo hacen algunas. No tengo manos de ángel y mi voz es fuerte como si hablara con enojo. Soy así porque soy elquina.iQue Dios me ampare mi debilidad! (citado en Bahamonde 26).

En la primera parte de este texto el sujeto expresa su imposibilidad de establecer relaciones espontáneas con "la gente”, y aquí se refiere a la gente en general, a causa del efecto que produce su forma de relacionarse: "me profesan veneración”, “me demuestran desconfianza o una cierta dolorosa frialdad”. Ya sea por exceso de admiración o por desprecio, el efecto es la distancia. Lo cual "resulta extraño" para el sujeto porque implícitamente considera que sus relaciones debieran ser cordiales y fáciles. La distancia surge de una serie de negaciones que atribuye a su forma de ser y a su forma de actuar: "no tengo condiciones", “no consigo”. Es decir, que su comportamiento no encaja en un modelo pre-establecido de relaciones humanas.

Luego trata de explicarse y de explicar al destinatario (el texto parece ser una carta a la madre) la causa de su alejamiento o distancia de la gente: "Capaz que esto se deba a que 
todo en mí tiene un fondo intelectual. Primero soy eso: una intelectual. Y después, pero muy después, recién soy mujer, sin mucha gracia humana, y sin mucha comunicación”. La afirmación es, en apariencia, demasiado contundente. No admite dudas por parte del sujeto. Su lugar como intelectual lo tiene muy claro. No así su lugar como "mujer intelectual”. El hecho de ser intelectual y de ser mujer parecen pertenecer a distintas escalas en una jerarquía en la que el intelecto predomina sobre el género. Los niveles resultan ser incompatibles. Pero simultáneamente, ser intelectual, también implica ser "eso". El uso del neutro nuevamente introduce la ambigüedad de géneros, con lo cual se nivela la jerarquía intelectual-femenino, con intelectual, que implícitamente supone intelectual-masculino. La tensión entre rol femenino e intelectual se polariza en la obra de Mistral a través de la contradicción entre los estereotipos femeninos que presenta y su propia labor como profesional. Obviamente esta contradicción está presente en ella misma: por ser mujer intelectual es que no tiene la "gracia” que se pide a las mujeres ni la facultad de comunicarse cordialmente con el otro.

Una vez afirmado su contradictorio lugar como intelectual surge la segunda contradicción: “¿Y cómo entonces hierve en mí esa fuerza pasional por estrujar mis dolores?”. Pareciera ser por la forma en que está estructurado el texto que “ser intelectual”, es un terreno que está bajo control, pero que puede ser súbitamente desestructurado por una fuerza pasional que compele al sujeto a “estrujar” sus dolores. La pasión está en el acto de “estrujar”, más que en la aparente pasión amorosa. La acción de "estrujar” podría considerarse como una metáfora de la escritura. Escribir para el sujeto es como estrujar los dolores, agotarlos, extraer de ellos todo el partido posible hasta sacarles el jugo que es el texto. La referencia al suicida Romelio Ureta, sobre quien Mistral escribió muchos poemas en Desolación, hace evidente la relación entre estrujar y escritura. Es entonces la pasión por estrujar la que compele a la escritura.

¿Pero cuál sería la labor de la intelectual? Aparentemente sería la de “convertir”: “Vivo ciega de pasión y de poesía, tratando de convertir los dos torrentes en los impulsos profundos de mi vida”. Aquí, pasión por estrujar y poesía íntimamente relacionados, deben ser “convertidos” en impulsos de vida. La conclusión lógica de este texto debiera ser que la labor de la intelectual fuera la de convertir pasión en poesía, estrujar en escribir. Pero el mismo texto no admite esta conclusión puesto que todavía en el sujeto conviven casi caóticamente diversas categorías confusas sobre la identidad femenina y su rol profesional. Este es el caldo de cultivo que está generando el nacimiento del seudónimo, y es en el mismo año que aparece este texto, 1911, que lo usa por primera vez. Es interesante notar, sin pretender establecer una relación entre los dos hechos puesto que Lucila no se enteró inmediatamente, que su padre, Don Gerónimo Godoy, muere el 30 de agosto de ese año en un hospital en Copiapó (Bahamonde 38).

Un mes más tarde, el primero de octubre de 1911, El Mercurio de Antofagasta publica un cuento titulado "El rival”, firmado por primera vez por Gabriela Mistraly. Llama la atención en los primeros usos del seudónimo la reaparición de la "Y” en Mistraly, que a veces se traslada a la “i” latina en Mystral y que luego desaparece. A este respecto Mistral dice:

Se me ocurrió entonces así buscar un nombre de viento que pudiera ser de persona y encontré el mistral y lo adopté agregándole aquella "Y" primitiva con lo que quedó Mistraly, luego tiré la "Y” y dejaba el nombre actual (citado en Giménez 37). 
La recuperación de la "Y” primitiva, aquella "Y” con la cual firmaba sus primeros escritos sugiere por un lado, un deseo del sujeto de condensar las anteriores formas de representación en el nuevo nombre, y por el otro parece indicar que este nombre no está todavía completo: Gabriela Mistral y ... ¿̇Y qué? Evidentemente, al “tirar” la "Y” Lucila “tira” ciertas imágenes de sí misma que ya no la representan, logra desprenderse de una representación pasada. El seudónimo adquiere su forma definitiva y, como mostraré más abajo, en este nombre se encuentran en germen las futuras formas de representación del sujeto poético mistraliano.

Dentro del contexto de las relaciones contradictorias con las que Mistral se autofigura, cobra gran importancia el relato que inaugura el uso de su seudónimo. "El rival” puede leerse como una metáfora del cambio de nombre. El protagonista de la historia que significativamente se llama Gabriel narra a dos amigos su lucha contra un rival invisible, el cual se apodera de sus tres amores, tres mujeres enfermizas. La muerte, "el” rival del título se materializa al final del cuento bajo la forma de un espectro y triunfa sobre la figura de Gabriel quien se sume en una atmósfera de ultratumba. El conflicto puede leerse como el proceso de elaboración del seudónimo que supone el entierro o la muerte de previas formas de representación.

El hecho de que Mistral inaugure el uso del seudónimo con esta narración hace que pueda otorgársele una dimensión autobiográfica, puesto que se produce una alineación entre dos nombres: el nombre de la autora y el nombre del personaje. Paul de Man sugiere en su ensayo “Autobiography as Defacement” que:

The autobiographical moment happens as an alignment between the two subjects involved in the process of reading in which they determine each other by mutual reflective substitution (70).

La alineación se produce por medio de la coincidencia entre el nombre de autor, representado por el seudónimo, Gabriela, y la versión masculina de este mismo nombre, Gabriel, quien no sólo es el protagonista de la narración, sino que también se apodera del discurso narrativo, desplazando casi por completo al narrador omnisciente.

Es interesante la descripción que el narrador hace del personaje, al abrir y cerrar el relato, porque parece estar consciente simultáneamente del cambio de nombre. Al comienzo del relato, el protagonista es presentado de la siguiente manera:

El que había callado, Gabriel, el de carácter enigmático, gustador de los cuentos terribles, habló luego (Citado en Bahamonde 116).

Esto mismo puede transcribirse de otra manera: “Gabriel/a, el/la que había callado (hasta ahora, que comienza a usar el seudónimo), el/la de carácter enigmático, gustador/a de cuentos terribles, habló”. Y desde este momento no deja de hablar/escribir. La inversión genérica es significativa porque sugiere que la figura masculina habilita un nuevo sistema de figuraciones que posibilita la entrada en el mundo de los "cuentos terribles", o sea en el terreno de la ficción que produce el seudónimo. La trama de “El rival” muestra las sucesivas transformaciones de Gabriel a través de las relaciones que establece con sus tres amadas. 
Antes de conocer a su primer amor, Gabriel se presenta de la siguiente manera:

Tenía yo dieciocho años, y aunque de esa edad a mis treinta de hoy la distancia no es enorme, existe entre mi físico de aquella época y el actual diferencia imponderable. Era yo de rostro lozano, ni leía entonces los cuentos de Poe ni amaba a Baudelaire, ni llevaba entre las cejas este gran surco que llevo hoy lleno de sombra. Y era risueño, de otra risa, de niño sano y harto (117).

¿Qué es lo que produce el cambio en esta figura fragmentada de Gabriel/joven en Gabriel/sombrío? Su atracción por el mundo de la ficción. Con respecto a su primera amada dice:

Porque era bella como una ficción de pintor, y después de verla largo tiempo, era imposible amar otra cosa que lo semejante a ella (117).

La comparación de la belleza de la amada con la ficción indica que las preferencias de Gabriel entran en el terreno de las figuras. Ya no puede amar otra cosa que "lo semejante a ella”, es decir, que Gabriel construye un modelo de belleza basado en una cierta estética que en este caso se relaciona con la pintura. Más adelante en la historia, Gabriel define su modelo de belleza:

Era su belleza de gracilidad floral. Tenía esa palidez que hasta hoy es para mí atributo ineludible de belleza. Para mí son odiosas esas mujeres de formas exuberantes y de mejillas rojas. Yo no amo esa expresión de vida desbordada y pasional (118).

Gabriel, hasta los diez y ocho años se presenta con un "rostro lozano", es decir, de “mejillas rojas”. Era "sano y harto”, es decir, de “formas exhuberantes”. Con lo cual puede concluirse que amaba "esa expresión de vida desbordada y pasional”. Vale la pena recordar aquí el texto mencionado anteriormente en el cual Lucila Godoy se figura como una mujer pasional.

¿Y cómo, entonces, hierve en mí esa fuerza pasional por estrujar mis dolores?[...] me confieso pasional. Vivo ciega de pasión y poesía [...] Me confieso pasional y por ello no le pido perdón a nadie (122).

En la figura de Lucila están condensadas las características que escinden la figura de Gabriel. Por un lado el joven Gabriel puede identificarse con Lucila por lo pasional, o vital. Por el otro, el Gabriel/sombrío se identifica con Lucila por su atracción por la estética enfermiza: ambos “estrujan” sus dolores. En Lucila están en germen las dos formas de representación, pero el cuento muestra el proceso por el cual, lo pasional o vital va a ser desplazado por lo enfermizo. La mirada dirigida hacia lo sombrío se inscribe dentro de una estética que pasa desde el romanticismo, al simbolismo y al decadentismo y modela tanto a Gabriel como a Gabriela, la autora del texto. Según Jaime Concha, 
Hay una línea de poetización que se complace en imaginar la disolución material del cuerpo del amado o de la amada. Este clima poético, en que el cadáver, el ataúd y la tumba son los centros de atracción imaginaria, flota de modo intermitente en la tradición lírica hispanoamericana (64).

La nueva figuración o la desfiguración que se produce en Gabriel/a, reponde a esta estética.

Una vez determinado el modelo estético ese primer amor muere, para que Gabriel/a entre en la segunda fase de su metamorfosis. Con su segundo amor, la pálida Lidia, la distancia entre Gabriel/a y la mujer como objeto de arte, como ficción, se hace más tenue, podría decirse que desaparece, puesto que según la perspectiva del hermano de Lidia, Gabriel lleva en sí un "mal terrible”, que se describe de la siguiente manera:

Eres sensible como una mujer la que más, tienes exquisiteces más fatales de sentimiento [...] Tú necesitas el contacto perenne de una vida lozana y vigorosa que te comunique su savia prolífica y te inocule energías. Gabriel, tú no querrás casarte con una mujer como Lidia, temperamento extraño en el que veo iguales síntomas que en ti. Se te parece como una hermana (120).

Es importante destacar que el "mal terrible” que aqueja a Gabriel es la feminización, Gabriel es "sensible como una mujer”, lo cual explica su atracción por las mujeres hipersensibles o enfermizas. Mistral muestra el caso de un hombre feminizado que fracasa en su intento de relacionarse con mujeres inaccesibles. Veladamente expone un caso de homosexualidad masculina. A nivel de la elaboración del seudónimo, la feminización de Gabriel está relacionada con el rechazo a cierta forma de representación de lo femenino, que tiene que ver con lo sano y vigoroso y con la identificación con un modelo que sale de la norma de lo considerado "sano" en el texto, es decir, con un modelo homosexual.

Con el tercer amor, que Gabriel llama su "tercera víctima”, es directamente el espectáculo de lo enfermizo lo que produce la vitalidad. Gabriel siente ante ella,

El anhelo de protegerla y de robarla al infortunio de la muerte. ¡Cosa extraña! Esa mujer era enferma y triste en tal grado que junto a ella yo sentía la sensación de la fuerza en mí y me creía pletórico de vida (124).

Pero esta vitalidad ante lo enfermizo transforma a Gabriel en agente de la muerte:

Esas brisas marinas confortantes me parecía que hacían el milagro en sus pobres pulmones [...] El ejercicio físico a la que la obligaba era enorme (124).

El médico del cuento dictamina: "Es por hacerla vivir que la ha matado” (125). Gabriel pasa a ser un emisario de la muerte. Ya en los dos casos anteriores, Gabriel participa en forma indirecta en la muerte de sus amadas: la primera muere de un susto al verlo caer de un caballo y la segunda muere cuando él se ausenta para visitar a sus padres. "El rival” del cuento, no sería la muerte, puesto que Gabriel parece ser su aliado, sino la vida, la vida heterosexual que Gabriel podría tener si estas mujeres fueran “sanas”. 
Es sobre todo la experiencia del enfrentamiento físico de Gabriel con la muerte, su rival/aliada, la que culmina el proceso de desfiguración o nueva figuración de Gabriela. En el velorio de la amada la muerte se personifica en un espectro que arrebata a la joven muerta de los regalos que le diera su novio: un medallón con un retrato de Gabriel y un anillo. Gabriel que está sólo en ese momento describe la escena:

$\mathrm{Y}$ entonces vi condensarse las sombras junto al catafalco y tomar una forma alta y delgadísima, borrosa al principio, pero que fue diseñando poco a poco sus contornos. Formóse primero una cabeza redondeada y desnuda, luego dos brazos larguísimos; hacia abajo un sayal uniforme y negro (126).

La formación del espectro materializa el modelo de figuración que se ha ido desarrollando a lo largo del cuento y que da cuerpo al seudónimo: es la prosopopeya. Según Paul de Man,

It is the figure of prosopopeia, the fiction of an apostrophe to an absent, deceased, or voiceless entity, which posists the possibility of the latter's reply and confers upon it the power of speech. Voice assumes mouth, eye, and finally face, a chain that is manifest in the etymology of the trope's name, prosopon poien, to confer a mask or a face (prosopon). Prosopopeia is the trope of autobiography, by which one's name [...] is made as intelligible and memorable as a face. Our topic deals with the giving and taking away of faces, with face and deface, figure, figuration and desfiguration (75-6).

La prosopopeya es la figura retórica que posibilita la respuesta de los entes sin voz, como los ausentes o los muertos y que les otorga el poder de la palabra. Por medio de la materialización del espectro, Gabriela provee una figura, un cuerpo, una cara, una máscara a su seudónimo y éste le abre las puertas al mundo de la ficción y de la poesía. La descripción de Gabriel al final del cuento muestra la transformación, “desfiguración”, o la nueva figuración que se produce una vez consumado el acto narrativo y una vez inaugurado el nuevo nombre:

Al terminar, su rostro estaba desfigurado. Sus grandes ojos abiertos miraban hacia la parte oscura de la sala como si ella se poblase de visiones (127).

La figura de Gabriel/a/espectro es la encargada de terminar con los restos del Gabriel vital identificado con la Lucila pasional. Según el relato de Gabriel, el espectro,

Con este brazo alzó la mano que llevaba el anillo y lo arrancó violentamente... Y con el otro buscó en el pecho el medallón. Sentí el trizarse del vidrio y el rodar del anillo que llegó hasta un rincón, en el mismo momento. Los pedazos del cristal se deslizaron sobre el sudario y cayeron a un lado. Hecho esto el fantasma fue borrándose hasta oscurecer el aposento. Yo rodé desvanecido. No recuerdo más (126).

La ambigüedad del demostrativo “este” en “este brazo”, identifica el brazo de la muerte con el brazo de Gabriel como perpetradores del despojo de los últimos atributos de Lucila. El desvanecimiento de Gabriel figura la muerte de Lucila. Y después de esta muerte ya no queda nada de ella. "No recuerdo más”, concluye Gabriel. 
Gabriela Mistral, por medio de esta historia y por medio del cambio de nombre entra en el terreno de las figuras, de las figuras retóricas que posibilitan diversas formas de autofiguración, entre las que se incluye veladamente la de la homosexualidad. Para acceder al mundo de las figuras, es decir al mundo de la escritura, el yo debe escindirse, fragmentarse. La desfiguración del rostro de Gabriel/a enmascara la fragmentación de Lucila. Gabriela Mistral como seudónimo o nombre de autor nace de las cenizas del nombre de Lucila Godoy.

Es tal vez por este motivo que Mistral desarrolla esta fascinación por la atmósfera mortuoria. No es casual entonces su obsesión por el suicidio de Romelio Ureta, el que especularmente o espectacularmente estaría mostrando la muerte de Lucila Godoy. La estética de la tumba delinea una de las formas de autofiguración más fuerte en la obra de Mistral. Y es gracias a los “Sonetos de la muerte”, ganadores de los Juegos Florales de 1914, tres años después de la publicación de “El rival” que Gabriela Mistral inicia su carrera hacia la posteridad.

A partir de la publicación de “El rival”, los textos poéticos de Mistral aparecerán firmados con el nombre Gabriela Mistraly. Pero los que se refieren a su profesión como maestra, como por ejemplo, Cuentos (oyendo los del Kindergarten) de enero de 1912, conservan el nombre de Lucila Godoy Alcayaga, o simplemente Lucila Godoy. Esta dicotomía se extiende también a la vida privada de la autora. ${ }^{1}$ Hasta el año 1922, sus cartas personales a Manuel Magallanes Moure las firma como Lucila, Tu Lucila o simplemente con una L. Pero las cartas profesionales referidas al oficio de escritora las firma Gabriela Mistral como puede leerse en las cartas a Eduardo Barrios de 1915, a Amado Nervo de 1916 y 1917, y a Alfonso Reyes de 1923.

A comienzos de 1913 “El Diario Ilustrado” de Santiago publica El himno cuotidiano bajo el nombre de Gabriela Mistral. La "Y" final cae y su seudónimo se mantiene sin alteraciones hasta el final de su vida. El hecho de ganar los Juegos Florales en 1914 afirma la solidez de su seudónimo en Chile. Y su nombramiento en México lo arraiga a nivel internacional. Es el triunfo del seudónimo y de lo que éste representa.

RESONANCIAS DEL SEUDÓNIMO

Pero, ¿qué es un seudónimo? Según la etimología de la palabra latina pseudonimus, el seudónimo sería un nombre falso que oculta el nombre verdadero. En lugar de inscribir la cuestión del seudónimo en el discurso de lo verdadero y lo falso propongo que la elección de un seudónimo se relaciona con un deseo por parte del autor de mostrar cierto tipo de autofiguración que no puede leerse en el nombre original, por ejemplo, cuando un autor elige un nombre más "literario" para autorizar su obra, como en el caso de José Neftalí Reyes, más conocido por su seudónimo Pablo Neruda. Si se instala la discusión sobre el seudónimo en la cuestión del género, puede verse que las mujeres han tenido razones diferentes para “ocultar” el patronímico. Gilbert y Gubar sugieren que en el siglo XIX, el seudónimo masculino funcionó como una máscara para las mujeres para ocultar su sexo. Pero además, el seudónimo adquiere otra función para las mujeres:

${ }^{1}$ Soledad Bianchi en su ensayo "Amar es amargo ejercicio. (Cartas de amor de Gabriela Mistral)”, Palabra cómplice 87-94, analiza la autorrepresentación de Lucila en su correspondencia amorosa. 
The pseudonym began to function more prominently as name of power, the mark of a private christening into a second self, a rebirth into linguistic primacy (“Cermonie”s 229).

El seudónimo en Gabriela Mistral funciona como un “nombre de poder”, deliberadamente elegido, con el cual se renuevan la ascendencia, el lugar de nacimiento y las figuraciones genéricas, para establecer la primacía de la persona literaria, la persona profesional, sobre la persona familiar.

El nombre Gabriela es el femenino de Gabriel, nombre - de origen hebreo- del arcángel de la Anunciación. En el Diccionario de Angeles de Davidson, se define la palabra “ángel”:

The word derives from angiras (Sanskrit), a divine spirit; from the Persian angaros, a courier; from the Greek angelos, meaning a messanger [...] In popular use an angel denotes, generally, a supernatural being intermediate between God and man (20).

Un ángel es un espíritu divino que actúa como mensajero entre Dios y los hombres. El profeta y su descendiente el poeta, cumplen la misma función. Al elegir Mistral un nombre de ángel, no sólo se instaura como mensajera de Dios, sino que se apropia de una genealogía celestial, cuyos significantes se remontan a las lenguas más antiguas de nuestra cultura: el sánscrito, el persa, el babilonio, de donde proviene el nombre Gabriel. El término “arcángel” se usa para denomimar una categoría superior en la jerarquía angelical. En este sentido de "gran ángel” es considerado el Arcángel Gabriel, quien ocupa uno de los lugares más altos en la escala divina. Es el ángel de la anunciación, de la resurrección, de la misericordia, de la venganza, de la muerte y de la revelación. Gabriel preside en el Paraíso, y aunque es el príncipe del primer cielo, se dice que se sienta a la izquierda de Dios. En la tradición cristiana, se lo conoce principalmente por ser el Angel de la Anunciación: el ángel que anuncia a María que va a ser la madre de Dios. La oración a la virgen, "Dios te salve María, llena eres de Gracia, el Señor es contigo...” repite las palabras que pronuncia Gabriel (Davidson 51).

La elección del nombre Gabriela configura una nueva persona que se opone a la figura de la Virgen que encarnaba el nombre María del Perpetuo Socorro. Básicamente, se apropia de un rol activo como agente de revelación y de muerte. No es Gabriela la que concibe sino la que anuncia la concepción. Los estereotipos de la maternidad que desarrolla Mistral en su obra poética se encuentran en franca contradicción con las implicaciones de su nombre.

El nombre Gabriela también crea una ascendencia literaria. Uno de los autores que Mistral admiraba en aquella época era Gabriele D’Annunzio, cuyo nombre también se asocia al Arcángel de la Anunciación. En más de una oportunidad se refiere a este autor. En una carta a Eduardo Barrios, datada en 1924, dice: "y siendo como soy, una insigne bebedora de palabras o períodos líricos brillantes (de D’Annunzio se me quedan páginas enteras)” (citado en Vargas Saavedra 37). Además de su admiración por el estilo literario, Mistral se siente atraída por la atmósfera de decadencia que crea este autor y la traslada a sus propios escritos:

La casa tenía todo el aire de abandonada; pero un domingo se abrió la ventana mayor y asomó una señora un rostro de cuento de D’Annunzio. Me aproximé a decirle alguna 
excusa, y ella no me contestó nada, me dio una sonrisa inolvidable, próxima por la dulzura y distante por la demencia (Grandeza 85).

El ambiente decadentista unido a la atracción por la locura conforman la atmósfera de "El rival”, como mostré más arriba. Aunque a lo largo de los años Mistral se va desprendiendo de este ambiente, la representación de la locura se mantiene hasta el final de su vida y modela otra de las formas de figuración de su sujeto lírico. Como puede observarse, ya está inscripto en el seudónimo que elige.

El apellido Mistral, establece así como el nombre una ascendencia literaria. A pesar de las afirmaciones de Mistral al respecto las relaciones entre Federico Mistral y el seudónimo son inevitables:

\begin{abstract}
Una vez tuve que mentir sobre este punto de mi nombre literario [...] En aquella ocasión visitaba con otras personalidades de la Sociedad de las Naciones al Presidente de Francia, quien nos invitó a almorzar. Durante el almuerzo me interrogó si mi nombre lo había adoptado por Federico Mistral, a lo que respondí que sí porque en aquel momento no era posible responder otra cosa. Y no es que yo no admire a Mistral. Por el contrario, lo quiero enormemente porque es el santo del folklore provenzal (citado en Giménez 37).
\end{abstract}

Aunque estas afirmaciones son posteriores a la elección del seudónimo, en el poema "Mis libros" Mistral elige al poeta provenzal como uno de sus precursores literarios. Junto con la Biblia, Dante, San Francisco de Asís y Amado Nervo se encuentra Federico Mistral, lo cual prueba la ascendencia que este poeta tuvo en ella. Con respecto a su obra Mireya, dice:

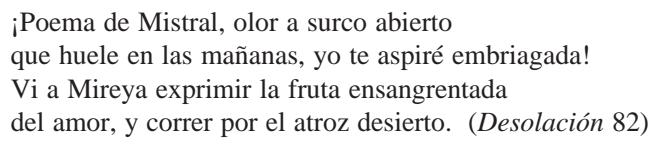

Con el poema de Mistral se establece una relación que se experimenta a través del cuerpo, por medio de los sentidos. El poema "huele" y se "aspira" como un olor. Los personajes se "ven". Y en esta especie de performance se dramatizan los avatares del amorpasión. Mireya “exprime” la fruta ensangrentada del amor casi doblando la fuerza pasional que llevaba a Lucila a “estrujar (los) dolores”. Mireya y Gabriela comparten esa pasión por exprimir los dolores causados por el amor. Y en el caso de Mistral se traduce en textos poéticos.

Otro aspecto que es importante destacar es el lugar preponderante que se asigna a la naturaleza, por medio de la elección de uno de sus elementos, el aire, como otra modalidad de autofiguración. Mistral enfatiza que su predilección por el viento es lo que la llevó a elegir el seudónimo:

Yo he adorado siempre el viento. De todos los elementos es con el viento con el que me he entendido mejor. Siempre en las tardes, después que terminaba mis labores escolares, me iba hacia un punto alto en la escarpa y ahí por largo rato me sumergía en su soplo. Es 
curioso, pero el viento me produce el mismo efecto que a los borrachos el vino, y después de este baño me siento mejor. Estoy contenta, todo me llama a la risa y hago versos. Se me ocurrió así buscar un nombre de viento que pudiera ser de persona y encontré el mistral y lo adopté agregándole aquella "Y” primitiva [...] (citado en Giménez 37).

La relación de causa-efecto entre viento y escritura es lo que produce según Mistral el seudónimo. Pero hay también otros aspectos que bordean este nombre que me parece importante destacar. El mistral es un viento violento, frío, turbulento y seco que sopla desde el sector norte sobre la Francia mediterránea. Para el autor provenzal, Federico Mistral, este nombre, que es un toponímico, puesto que es el nombre del viento de un lugar geográfico específico, corresponde a su interés por preservar la lengua y las tradiciones de su región. El caso de Gabriela Mistral es más complicado. Reemplaza su patronímico hispanoamericano, Godoy, por un toponímico francés, Mistral. Es decir que en la elección de su apellido reniega no sólo de los lazos familiares que la incluyen en una estructura patriarcal, sino de su nacionalidad chilena y por ende de su filiación americana. A través de su apellido, Mistral elige su lugar geográfico de nacimiento: el sur de Francia. Esta elección lleva en ciernes su futura autofiguración como "vagabunda” o como "extranjera” palpable en su propia vida. Mistral vivió treinta y tres años en Chile y treinta y cuatro fuera de Chile. A causa de su profesión como maestra en Chile y como diplomática en el exterior, nunca tuvo un lugar fijo de residencia. La elección de un apellido topónimo francés revela la relación contradictoria de Mistral con su país natal.

Para terminar con este aspecto me interesa destacar que, etimológicamente, mistral como viento deriva de "maestral" por ser un viento dominante. La figura de la maestra, aunque modificada por el carácter violento del mistral, está implícita en el seudónimo. En el apellido Mistral hay entonces la elección de una ascendencia, la elección de un lugar de nacimiento y la referencia a una profesión, la docencia, con la cual la poeta tiene ambiguas relaciones. A pesar de los poemas en que incentiva y aplaude la labor de las maestras, en algunas de las cartas de amor a Magallanes Moure datadas alrededor de 1915, Mistral deja ver los entretelones de la tarea docente:

A mi me ha salvado la enseñanza. ¡Es tan vulgar y tan seca! Hay períodos en que yo trabajo salvajemente en cosas que ni aún necesito hacer, para gastarme esta exhuberancia de fuerzas, para fatigarme el espíritu inquieto! (105)

¿Querrá Ud. evitarme el ridículo, que arrojado sobre una maestra es más lamentable que en cualquier otro caso? (114)

Soy para la gente que trabaja conmigo, excepción hecha de la directora, cordial sin amistad alguna; la experiencia me ha hecho así. Mis rarezas sanas, que a nadie dañan, son interpretadas mal por la gente "sensata y correcta” y de ahí la distancia y el frío que hago entre mis compañeras y yo. (125)

A pesar de las adversidades que debió superar es impresionante la vertiginosa carrera docente que realiza Mistral y que le permite trascender su destino pueblerino. Juan Villegas Morales demuestra que Mistral representa un caso ejemplar de escritor apoyado por el 
Estado. En muy poco tiempo Mistral logra el más alto cargo que un docente puede aspirar en la estructura educacional chilena, el de Directora de una escuela secundaria. Esto llevaría normalmente treinta años de carrera. El salto más fuerte se produce entre 1912 y 1918, cuando asciende de Inspectora a Directora, y que justamente coincide con su reconocimiento como poeta, gracias a los “Sonetos de la Muerte”. Después de su estadía en México, Mistral vuelve a Chile y en 1925, se jubila como profesora, a los treinta y seis años de edad, después de sólo diez y seis años de labor. Posteriormente, inicia su carrera diplomática, que es tan deslumbrante como su carrera docente. Villegas Morales muestra las razones ideológicas que sustentan esta función del Estado como mecenas. Ante la disminución del poder político de la oligarquía agraria hacia fines del siglo XIX,

la nueva clase (media) necesitaba de una fuente de prestigio que sustituyese los valores de familia, tradición y riqueza. Afirma, entonces, los valores de la calidad del ingenio, del intelecto y acentúa la antigua dicotomía del valor de nacimiento opuesto a valor personal, la riqueza material opuesta a la riqueza de espíritu (96).

Según Villegas, la imagen del mundo y especialmente la imagen de la mujer que presenta Mistral, adquieren gran importancia para los intereses de la clase media en el poder. La figura de la maestra que presenta Mistral coincide por ejemplo con el slogan de la campaña presidencial de Aguirre Cerda, “gobernar es educar”. Para Villegas,

Gabriela Mistral no sólo idealizó la maestra sino que ella misma alcanzó una especie de aureola de la maestra ideal a través de sus creaciones en torno a la maestra, los niños, sus canciones e himnos escolares (103).

La maestra ideal que Mistral representa en sus poemas está fuera de las pujas y rencillas que seguramente debió superar para lograr un ascenso tan vertiginoso. Pero es interesante notar que si Mistral representaba los intereses del poder político dominante, el poder político representaba para ella la vía que encauzaba su carrera. Y no es desatinado afirmar que Mistral manipuló esta figuración de sí misma para ascender profesionalmente.

Pese a las estereotipadas imágenes que Mistral presenta del rol femenino en la sociedad, la elección de un seudónimo o “nombre de poder” conlleva la afirmación de ciertas creencias sobre el rol profesional que Mistral juzgaba aptas para sí misma, en un nivel de igualdad con los hombres. En una ceremonia de graduación en la Universidad de Puerto Rico en 1931, Mistral afirma que la profesión es más importante que el amor, porque las parejas se deterioran con el tiempo, mientras que por el contrario la profesión se embellece.

Iría yo bastante más lejos todavía para asegurar a estos mozos de estación florida, que el oficio es cosa superiorísima al amor y aún más sólido bloque de amor. Suelo mirar la profesión sin ajadura, sin ningún estropeo de la costumbre, más bellamente bruñida mientras más vieja, verdadera Raquel y Lía a la que embellece cada hijo nuevo, en tanto que el cuadro de la pasión amorosa suelo verlo tan estropeado del uso, tan ensuciado por las pecas cotidianas del hábito, que entristece mirarle el de metal innoble que el tiempo rebaja de precio y envilece (Grandeza 18-9). 
Aunque la conferencia está dirigida a “mozos de estación florida” y no a “mozas”, se presenta en forma positiva la metáfora de la procreación, “un hijo nuevo”, como resultado de la experiencia profesional. Y, en cambio, la relación pasional, cuya consecuencia podría ser el nacimiento de un hijo, se presenta en forma derogativa. Estas palabras pronunciadas por Mistral, en el año 1931, parecen concluir con la discusión interna que generó la fragmentación de Lucila Godoy, en los inicios de su carrera profesional y que dió origen a Gabriela Mistral. Mistral toma partido por la profesión literaria, docente y diplomática, es decir, que "la intelectual”, logra “convertir” la pasión amorosa en los impulsos de su vida. El seudónimo que utiliza Lucila Godoy para firmar sus textos literarios en Chile se expande en múltiples direcciones y contiene no sólo a las diversas figuraciones que desarrolla por medio del sujeto lírico, sino a la persona pública que obtiene el premio Nobel en 1945.

\section{OBRAS CITADOS}

Bahamonde, Marcelo. Gabriela Mistral en Antofagasta. Santiago: Nascimiento, 1980.

Bianchi, Soledad. “'Amar es amargo ejercicio’. (Cartas de amor de Gabriela Mistral)”. Una palabra cómplice. Encuentro con Gabriela Mistral. Raquel Olea y Soledad Fariña, eds. Santiago: Isis Internacional-Casa de la Mujer La Morada, 1989. 39-48.

Breunig, Leroy C. "For a Poetics of the Psuedonym". The Romanic Review LXXV/2 (1984): 256-262.

Bosch, Velia. Teresa de la Parra (Conversación Biográfica). Caracas: Alfadil, 1986.

Concha, Jaime. Gabriela Mistral. Santiago: Júcar, 1987.

Davidson, Gustav. A Dictionary of Angels Including the Fallen Angels. New York: Free Press, 1968.

Gilbert, Sandra y Susan Gubar. "Ceremonies of the Alphabet. Female Grandmatologies and the Female Authorgraph”. New York Literary Forum 12-13 (1984).

Gili Gaya, Samuel. Curso superior de sintaxis española. Barcelona: Bibliograf, 1985.

Giménez, Onilda. La crítica literaria en la obra de Gabriela Mistral. Miami: Ediciones Universal, 1982.

Ludmer, Josefina. “Tretas del débil”. La sartén por el mango. Río Piedras: Huracán,1984. 47-54.

Man, Paul de. “Autobiography as Defacement”. The Rhetoric of Romanticism. New York: Columbia University Press, 1984. 67-81.

Mistral, Gabriela. Cartas de amor de Gabriela Mistral. Sergio Fernández de Larrain, ed. Santiago: Andrés Bello, 1978.

Desolación. Santiago: Andrés Bello, 1990.

Grandeza de los Oficios. Roque Esteban Scarpa, ed. Santiago: Andrés Bello, 1979.

Molloy, Sylvia. “Dos lecturas del Cisne”. La sartén por el mango. Río Piedras: Huracán, 1984. 57-69.

Vargas Saavedra, Luis. Epistolario de Gabriela Mistral y Eduardo Barrios. Santiago: Abaco, 1988.

Villegas Morales, Juan. “El estado como mecenas: el caso de Gabriela Mistral”. Estudios sobre poesía chilena. Santiago: Nascimiento, 1980. 95-104. 